\title{
Anisotropic dehydration of hydrogel surfaces
}

\author{
Georgia Kaklamani $^{1}$ - David Cheneler ${ }^{2}$ Liam M. Grover ${ }^{3} \cdot$ Michael J. Adams $^{3}$. \\ Spiros H. Anastasiadis ${ }^{1,4} \cdot$ James Bowen $^{5}$
}

Received: 20 June 2017/ Accepted: 14 October 2017/Published online: 23 October 2017

(c) The Author(s) 2017. This article is an open access publication

\begin{abstract}
Efforts to develop tissue-engineered skin for regenerative medicine have explored natural, synthetic, and hybrid hydrogels. The creation of a bilayer material, with the stratification exhibited by native skin, is a complex problem. The mechanically robust, waterproof epidermis presents the stratum corneum at the tissue/air interface, which confers many of these protective properties. In this work, we explore the effect of high temperatures on alginate hydrogels, which are widely employed for tissue engineering due to their excellent mechanical properties and cellular compatibility. In particular, we investigate the rapid dehydration of the hydrogel surface which occurs following local exposure to heated surfaces with temperatures in the range $100-200{ }^{\circ} \mathrm{C}$. We report the creation of a mechanically strengthened hydrogel surface, with improved puncture resistance and increased coefficient of friction, compared to an unheated surface. The use of a mechanical restraint during heating promoted differences in the rate of mass loss; the rate of temperature increase within the hydrogel, in the presence and absence of restraint, is simulated and discussed. It is hoped that the
\end{abstract}

James Bowen

james.bowen@open.ac.uk

1 Institute of Electronic Structure and Laser, Foundation for Research and Technology Hellas, Heraklion, Crete, Greece

2 Engineering Department, Lancaster University, Bailrigg, Lancaster LA1 4YR, UK

3 School of Chemical Engineering, The University of Birmingham, Edgbaston B15 2TT, UK

4 Department of Chemistry, University of Crete, Heraklion, Crete, Greece

5 Department of Engineering and Innovation, The Open University, Milton Keynes MK7 6AA, UK results will be of use in the development of processes suitable for preparing skin-like analogues; application areas could include wound healing and skin restoration.

Keywords Alginate - Dehydration · Hydrogel ·

Polysaccharide $\cdot$ Skin $\cdot$ Stratification

\section{Introduction}

Biological tissues are highly organized and stratified structures. Complex tissue architectures are composed of different cell types with specific functions and locations. The interaction between them is conducted via their extracellular matrix. The interfaces between tissues are also complex and not easily distinguishable (Dormer et al. 2010). Tissue engineering aims to develop and mimic such architectures in vitro; various methods having been developed to simulate tissue complexity and allow interaction between different cell types, proteins, implanted materials, and scaffolds (Lee et al. 2009). Methods include 3D printing, electrospinning, and cell-sheeting engineering, often requiring complicated manipulations or lengthy constructions (Grossin et al. 2009).

Skin, the largest organ of the body, exhibits a stratified and organized structure, providing a protective layer with multiple functions (Horch et al. 2005). Nerve fibres and sensory receptors permit the detection of touch, pain, and temperature (Adams et al. 2007; Adams et al. 2013). There is significant interest in developing skin analogues suitable for replacing real skin, accelerating wound healing, restoring burns, and functioning like native skin (MacNeil 2007).

Skin tissue is composed of two layers: epidermis, a waterproof barrier that excludes microbes and retains body 
fluids; and dermis, beneath the epidermis, which is a collagen-rich connective tissue (Hunt et al. 2009). Melanocytes impart skin colour and are found at the lower level of the epidermis, and fibroblasts are found at the dermal layer and are responsible for the strength of the skin (MacNeil 2007; Bannasch et al. 2003). Epidermis, the outer skin layer, has a surface called stratum corneum, which is a less hydrated surface layer presented at the air/skin interface. Stratum corneum is composed of dead cells formed from keratin and with thickness that varies from 10 to $15 \mu \mathrm{m}$ for humans (Johnson et al. 1993).

Significant progress has been made in the development of tissue-engineered skin (Shevchenko et al. 2010), the skin analogue produced using cells, extracellular matrix, and combinations thereof, although the use of autografts and allografts is associated with several limitations (Priya et al. 2008; Bello et al. 2001). Various methods have been utilized to achieve skin regeneration (Yang et al. 2000; Lechler and Fuchs 2005; Fuchs and Horsley 2008), or to manufacture skin products for wound healing. Most of the skin products that have been reported use a natural, synthetic, or hybrid hydrogel as a scaffold (Priya et al. 2008; Currie et al. 2001; Bakakrishnan et al. 2005; Boucard et al. 2007; Powell and Boyce 2009), for example the use of collagen matrix encapsulated with fibroblasts and seeded with keratinocytes (Yang et al. 2000). Due to the poor mechanical properties and difficulties of handling collagen hydrogel, hybrid collagen/ alginate scaffolds have also been produced (Kim et al. 2011). Other hybrid scaffolds for skin regeneration include chitosan-gelatin bilayers (Mao et al. 2003). Stratified materials have also been produced using polyelectrolyte multilayers alternated with cell-containing gel layers (Grossin et al. 2009).

Alginate has been used in tissue engineering for the regeneration of skin, bone, and cartilage due to its mechanical properties and cellular compatibility, having been used to support the growth of fibroblasts and keratinocytes (Hunt et al. 2009; Kim et al. 2011; Alsberg et al. 2001; Stevens et al. 2004). Alginate is a naturally occurring, non-toxic polysaccharide derived from brown algae (Augst et al. 2006). It is biodegradable and can be used to form hydrogels under cytocompatible conditions. Alginate hydrogels are formed through ionotropic gelation of dissolved alginate in the presence of multivalent cations such as $\mathrm{Mg}^{2+}, \mathrm{Ca}^{2+}, \mathrm{Sr}^{2+}$, and $\mathrm{Ba}^{2+}$ (Morch et al. 2006; Topuz et al. 2012), and can be gelled using the internal (Chan et al. 2002a, b) or the external gelation method (Hunt et al. 2010; Kaklamani et al. 2014). Alginate has also been used to produce hybrid hydrogels for tissue engineering applications (Choi et al. 1999), but no solution proposed yet fulfils all the requirements needed to accomplish functional stratified structures.
The aim of this work was to investigate processes by which hydrogels can be modified to provide a stratum corneum-like dehydrated surface layer. Using a high-temperature heat source directly in contact with the hydrogel, the effect of rapid dehydration by evaporative loss of water from the hydrogel surface was studied. The influence of temperature and contact duration was considered. The external gelation method was employed to produce hydrogel samples; alginate concentration was also varied and investigated. The purpose of this research is to develop processes which might be suitable for the preparation of skin-like analogues.

\section{Experimental}

\section{Materials}

All chemicals were sourced from Sigma Aldrich (UK) unless otherwise stated. Purities were $>99 \%$ in all cases. HPLC-grade $\mathrm{H}_{2} \mathrm{O}$ was employed throughout.

\section{Hydrogel preparation}

Hydrogels (HGs) were prepared using a previously reported external gelation method (Kaklamani et al. 2014). Briefly, sodium alginate $(\mathrm{NaAlg})$ solution was poured into a poly(styrene) mould (141.4 mm inside diameter, $9.0 \mathrm{~mm}$ inside height, Sterilin, UK) to a liquid height of $6 \mathrm{~mm}$ and allowed to gel in the presence of an aqueous solution of $\mathrm{CaCl}_{2}$ held at the upper and lower boundaries by porous microcellulose sheets. Prior to the addition of the aqueous $\mathrm{NaAlg}$ solution, stainless steel cylindrical spacers $(21 \mathrm{~mm}$ diameter, $6 \mathrm{~mm}$ height, Longshore Systems Engineering, UK) were placed at $60^{\circ}$ intervals around the inner edge of the mould to support the upper sheet. The volume of aqueous NaAlg solution required was $81.75 \mathrm{~mL}$. The upper sheet was held in place from above using a poly(styrene) support, filled with water to maintain close contact between the upper sheet and the NaAlg solution as it gelled, since some shrinkage was observed at the sample edges.

$\mathrm{NaAlg}$ powder was dissolved in $\mathrm{H}_{2} \mathrm{O}$ under agitated conditions at a temperature of $70{ }^{\circ} \mathrm{C}$ and stirred for a minimum of $2 \mathrm{~h}$ using a Stuart US-152 hot plate stirrer (Appleton Woods, UK). The concentration of the NaAlg solution was $2.5 \%(\mathrm{w} / \mathrm{v})$ and $5.0 \%(\mathrm{w} / \mathrm{v})$. An aqueous $\mathrm{CaCl}_{2}$ solution of $2 \mathrm{M}$ concentration was created by dissolving $\mathrm{CaCl}_{2}$ powder in water, whilst stirring, at room temperature; the solution was allowed to cool to room temperature of $18{ }^{\circ} \mathrm{C}$ prior to use. Microcellulose sheets (QL100, Fisherbrand, UK) were trimmed to match the shape of the poly(styrene) mould and immersed in aqueous $\mathrm{CaCl}_{2}$ solution for $5 \mathrm{~min}$ immediately prior to use. Samples 
(a) Gelation geometry (aerial and side views)

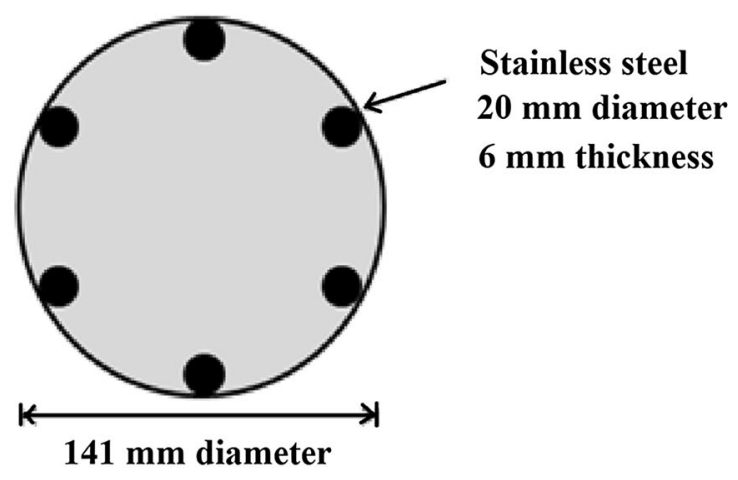

Key to figure

- - Saturated filter paper

Alignated solution

Gelled alignate

Stainless steel column

Poly (styrene) plate

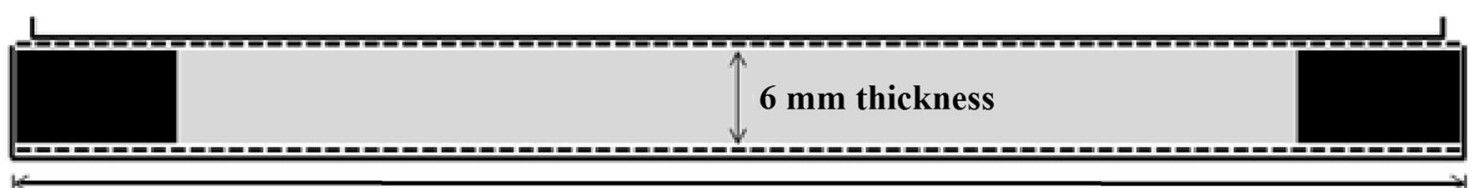

$141 \mathrm{~mm}$ diameter

\section{(b) Gelation schematic}

(i) Ungelled

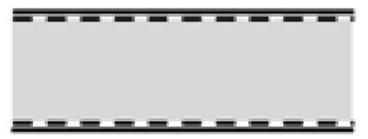

Fig. 1 Gelation geometry (a) and gelation schematic (b) showing (i) ungelled alginate solution, (ii)-(iii) progression of the gelation through the alginate solution as the cations diffuse into the alginate

were allowed to gel at $18{ }^{\circ} \mathrm{C}$ for $60 \mathrm{~min}$. The gelation geometry and schematic are shown in Fig. 1, reproduced from (Kaklamani et al. 2014). The solid gels which formed are hereafter referred to by their Young's modulus, which have also been previously reported (Kaklamani et al. 2014), and are $189 \pm 25 \mathrm{kPa} \quad(2.5 \% \quad \mathrm{w} / \mathrm{v}) \quad$ and $433 \pm 17 \mathrm{kPa}(5.0 \% \mathrm{w} / \mathrm{v})$.

\section{High-temperature dehydration}

Following HG preparation, rectangular specimens $(40 \mathrm{~mm} \times 40 \mathrm{~mm}$ ) were extracted using a cutting tool. HG specimens were heated for 4 min using a hot plate (Fisher Scientific, UK) at temperatures of 100,150 and $200{ }^{\circ} \mathrm{C}$, i.e., above the boiling point of water. Two different conditions were investigated-restrained and unrestrained. In the restrained condition, a $40 \mathrm{~mm}$ diameter stainless steel block (mass $=80 \mathrm{~g}$ ) was used to ensure intimate contact between the specimen and the hot plate. In the unrestrained condition, samples were prone to migrate across the surface of the hot plate, a thin layer of water vapour lubricating the contact. A schematic is shown in Fig. 2. The face of the (iii) Extensive gelation (iv) Gelled

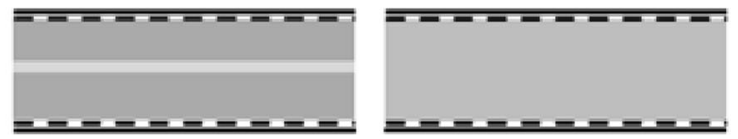

solution, generating cross-links, and (iv) the final, gelled alginate. Reproduced from (Kaklamani et al. 2014)

specimen adjacent to the hot plate is hereafter referred to as the Dehydrated Surface, while the opposite face is referred to as the Upper Surface. The mass of each specimen was measured before and after dehydration.

\section{Puncture testing}

Puncture testing was performed at $18{ }^{\circ} \mathrm{C}$ and $40 \%$ relative humidity using a Z030 mechanical tester (Zwick/Roell, UK). A stainless steel needle (gauge 19G, bevel point, Fisher Scientific, UK) was attached to a $5 \mathrm{~N}$ load cell. The puncture procedure involved approaching the needle towards the $\mathrm{HG}$ at a velocity of $5 \mathrm{~mm} / \mathrm{s}$. The specimen was oriented with the Dehydrated Surface presented upwards, facing the needle. Load-displacement data were recorded at $100 \mathrm{~Hz}$.

\section{Friction measurements}

Tribological measurements were performed on the Dehydrated Surface using a custom-built tribometer (Longshore Systems Engineering, UK). Tests employed a rotating stage 


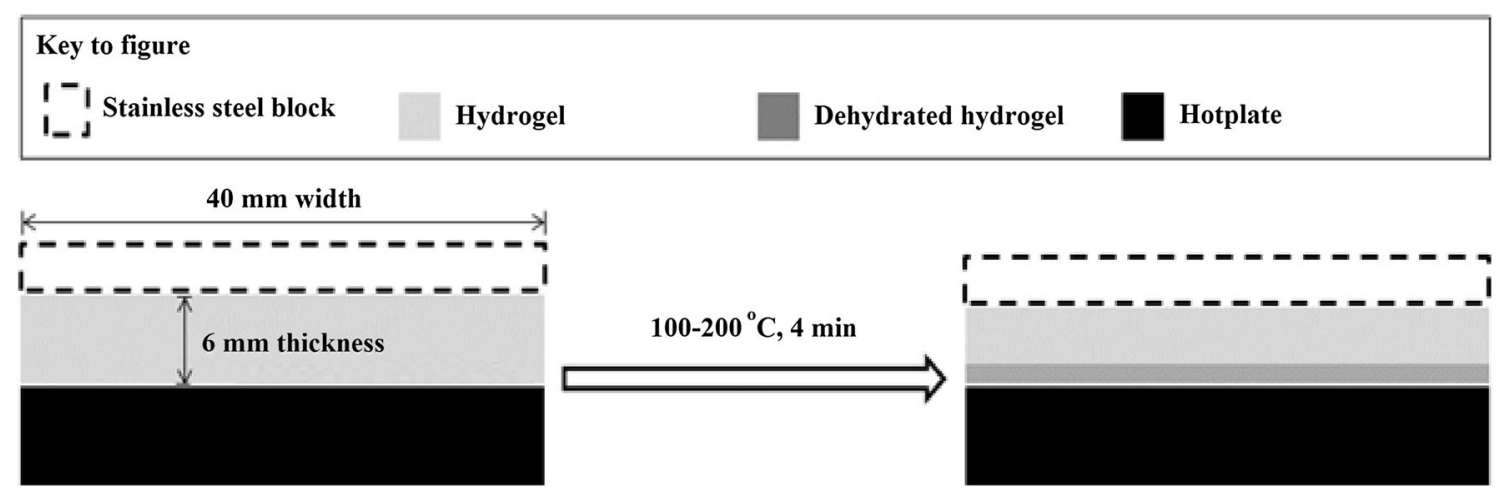

Fig. 2 Schematic showing the dehydration process. HGs are placed in contact with a hot plate at $100-200{ }^{\circ} \mathrm{C}$ for 4 min. Specimens were either restrained, using a stainless steel block, or unrestrained

travelling at $1 \mathrm{~mm} / \mathrm{s}$, on which the $\mathrm{HG}$ was securely immobilized. A sphere-on-flat contact geometry was adopted, employing $12.7 \mathrm{~mm}$-diameter spheres made of (i) glass and (ii) poly(propylene). Measurements were performed using an open loop control system. The normal load was $0.49 \pm 0.05 \mathrm{~N}$ for all tests.

\section{Results and discussion}

\section{Dehydration experiments}

Figure 3 shows the mass decrease for HGs dehydrated under restrained and unrestrained conditions. Increasing the dehydration temperature increases the $\mathrm{H}_{2} \mathrm{O}$ removed through evaporative loss, in accordance with expectations. HGs which were restrained exhibited smaller mass decreases at $100{ }^{\circ} \mathrm{C}$ than the unrestrained HGs. At $150{ }^{\circ} \mathrm{C}$ and $200{ }^{\circ} \mathrm{C}$, however, restrained HGs exhibited larger mass decreases than the unrestrained HGs. The different rate of heat loss to the ambient atmosphere, or to the restraining

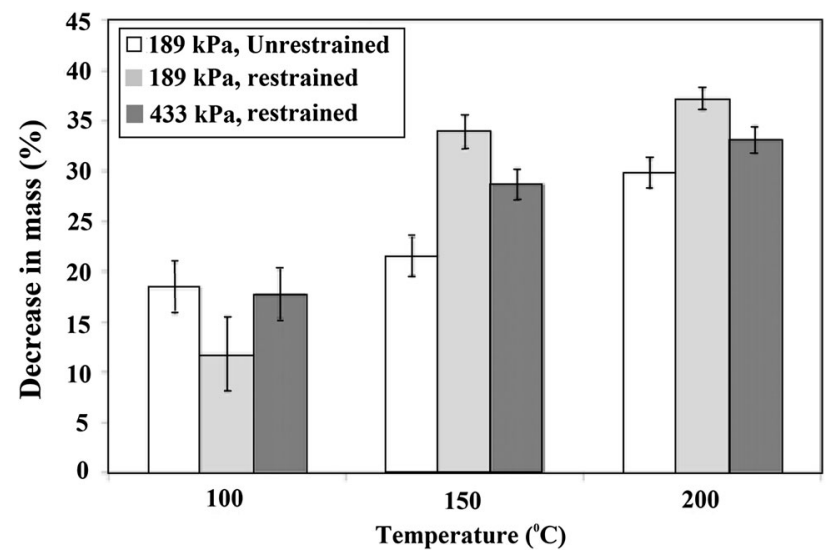

Fig. 3 Decrease in mass for $189 \mathrm{kPa}$ and $433 \mathrm{kPa}$ HGs during dehydration at 100,150 , and $200{ }^{\circ} \mathrm{C}$ in the restrained and unrestrained configurations disc, is thought to be the reason for the variations in mass decrease between experimental conditions. Once the restraining disc is heated sufficiently, the HG is effectively heated from both sides. This phenomenon is considered further in Sect. 3.4.

Figures 4, 5, and 6 show images of dehydrated HGs acquired using light microscopy. The profile view for the untreated $\mathrm{HG}$, Fig. 4a, shows that the $\mathrm{HG}$ is homogeneous through its thickness. As the dehydration temperature increases, a change in the HG surface topography can be observed in the Top View images. Furthermore, anisotropic layering can be observed in the Profile View images, particularly in Fig. 5c, d.

Restraining the samples during dehydration decreased the surface area from which water could evaporate. However, the metal disc was also heated during dehydration, by heat transfer through the HG. Hence, there was unrestricted heat and vapour loss at a solid/vapour interface for unrestrained samples, but this is not true for samples which were restrained. The thickness of the dehydrated layer increases with increasing temperature, in accordance with expectations. It should be noted that exposure to temperatures higher than $200{ }^{\circ} \mathrm{C}$ tended to lead to a burnt $\mathrm{HG}$ surface.

\section{Puncture testing}

Figure 7 shows the mean peak forces for (i) the untreated $\mathrm{HG}$, (ii) $\mathrm{HG}$ heated at $200{ }^{\circ} \mathrm{C}$ for $2 \mathrm{~min}$, and (iii) $\mathrm{HG}$ heated at $200{ }^{\circ} \mathrm{C}$ for $4 \mathrm{~min}$. Decreasing $\mathrm{HG}$ thickness is evidenced by the needle/counter-surface separation which decreases with increasing heating duration. Puncture tests revealed that puncture resistance increased with increasing dehydration time. The increased peak forces show that dehydration improves the mechanical properties of the HG surface. The dehydrated region of the HG exhibited a subsurface stratification, similar to a skin-like structure. The puncture force exhibited by the dehydrated $\mathrm{HG}$ was in 

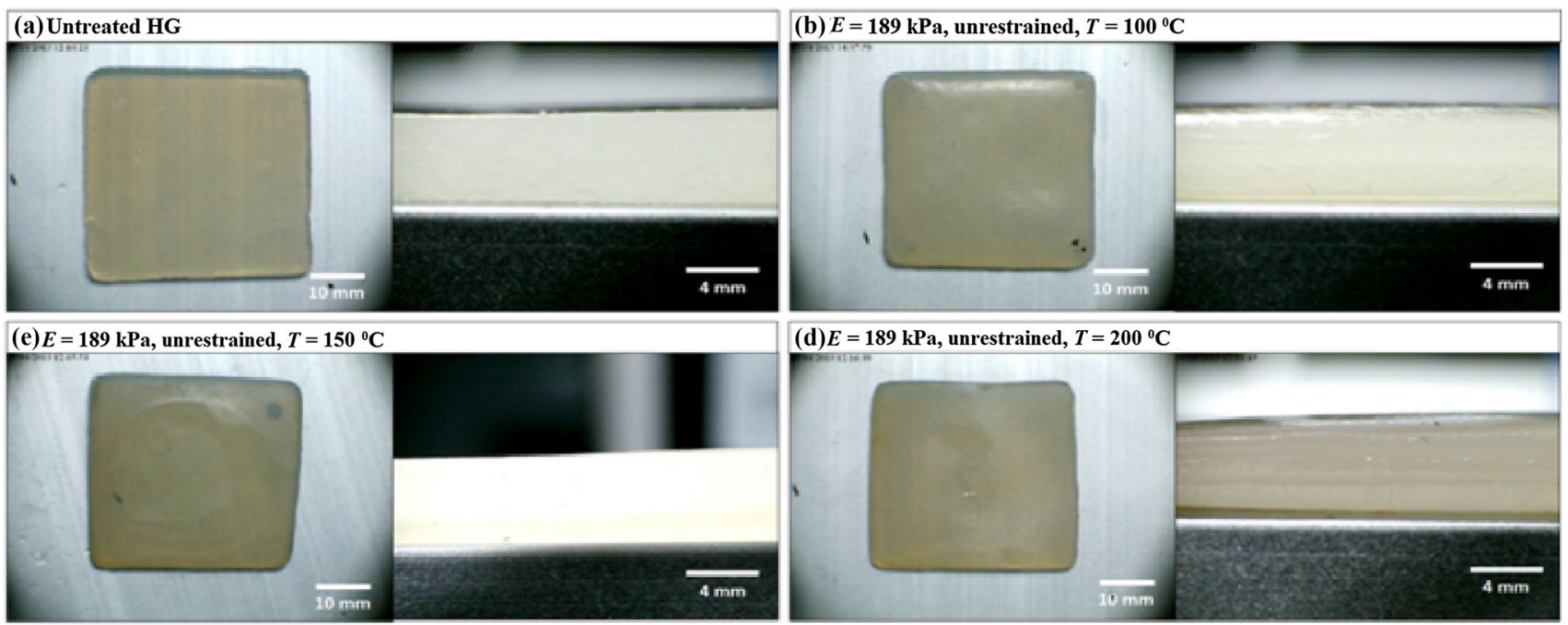

Fig. 4 Top view and profile view for $189 \mathrm{kPa}$ HGs during dehydration at 100,150 , and $200{ }^{\circ} \mathrm{C}$ in the unrestrained configuration
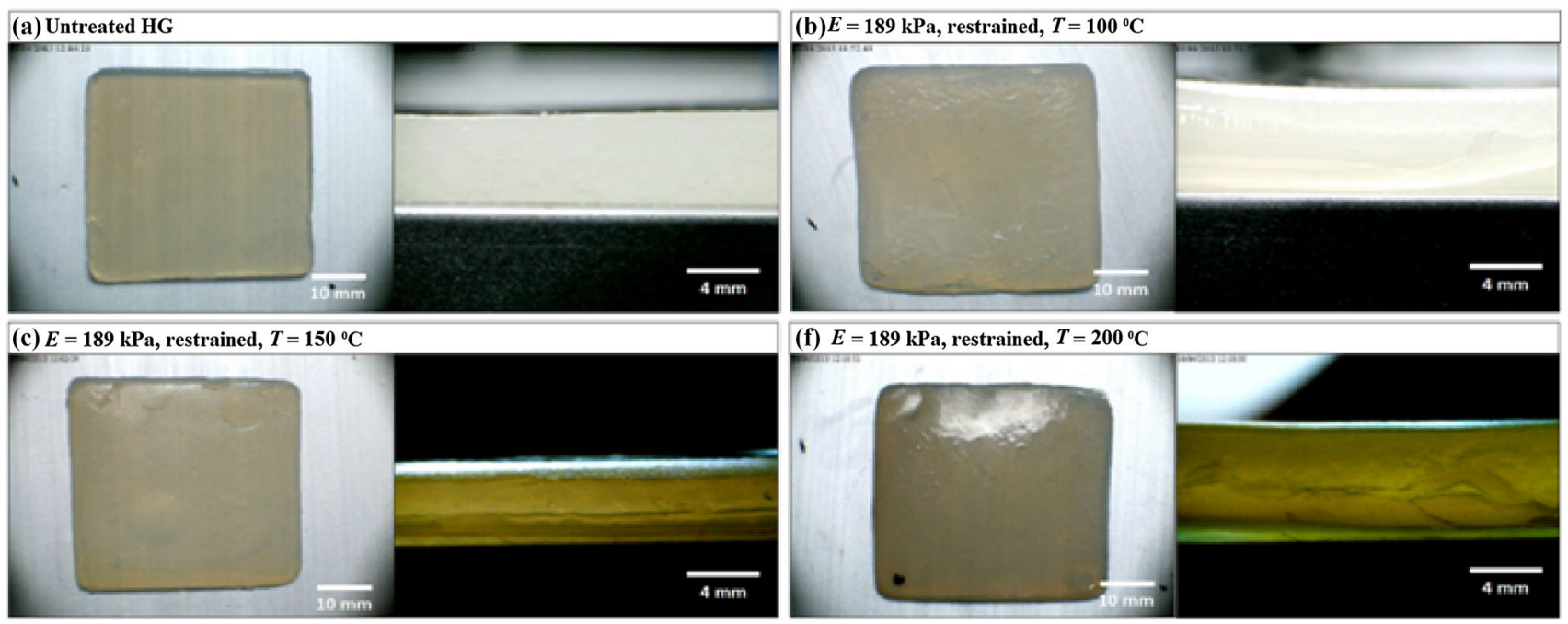

Fig. 5 Top view and profile view for $189 \mathrm{kPa}$ HGs during dehydration at 100,150 , and $200{ }^{\circ} \mathrm{C}$ in the restrained configuration

accordance with the puncture forces reported for needle insertion into skin (vanGerwen et al. 2012). The puncture resistance of HGs can be tailored by changing the cauterization time, an area for further investigation.

\section{Tribological testing versus glass and polypropylene}

The results of tribological testing of untreated and dehydrated $\left(200{ }^{\circ} \mathrm{C}, 4 \mathrm{~min}\right) \mathrm{HGs}$ versus glass and poly(propylene) are presented in Table 1 . The friction coefficient of the HG surface against both materials more than doubled due to dehydration. The glass surface is hydrophilic $\left(\theta_{\mathrm{H} 2 \mathrm{O}}=0^{\circ}\right)$, whereas poly(propylene is hydrophobic $\left(\theta_{\mathrm{H} 2 \mathrm{O}}=112^{\circ}\right)$. Hence, the $\mathrm{HG} /$ glass adhesion is greater than the HG/poly(propylene) adhesion, and therefore the friction coefficient is correspondingly larger for the
$\mathrm{HG} /$ glass than for HG/poly(propylene). Further, the dehydrated surface did not visibly undergo syneresis when under contact pressure from the spherical probe, which meant that lubricating effects were negligible compared to the untreated surface. The friction coefficients of the dehydrated HG surface compare favourably with those of human skin: $\mu_{\text {glass }}=0.26$ and $\mu_{\mathrm{PP}}=0.35$ (Adams et al. 2007).

\section{Effect of restraint on heating rate}

A heat transfer simulation of heating the restrained and unrestrained HG samples was performed using Energy2D (v2.9.5) (Xie 2012). The material properties used are shown in Table 2. The initial hot plate temperatures of 100, 

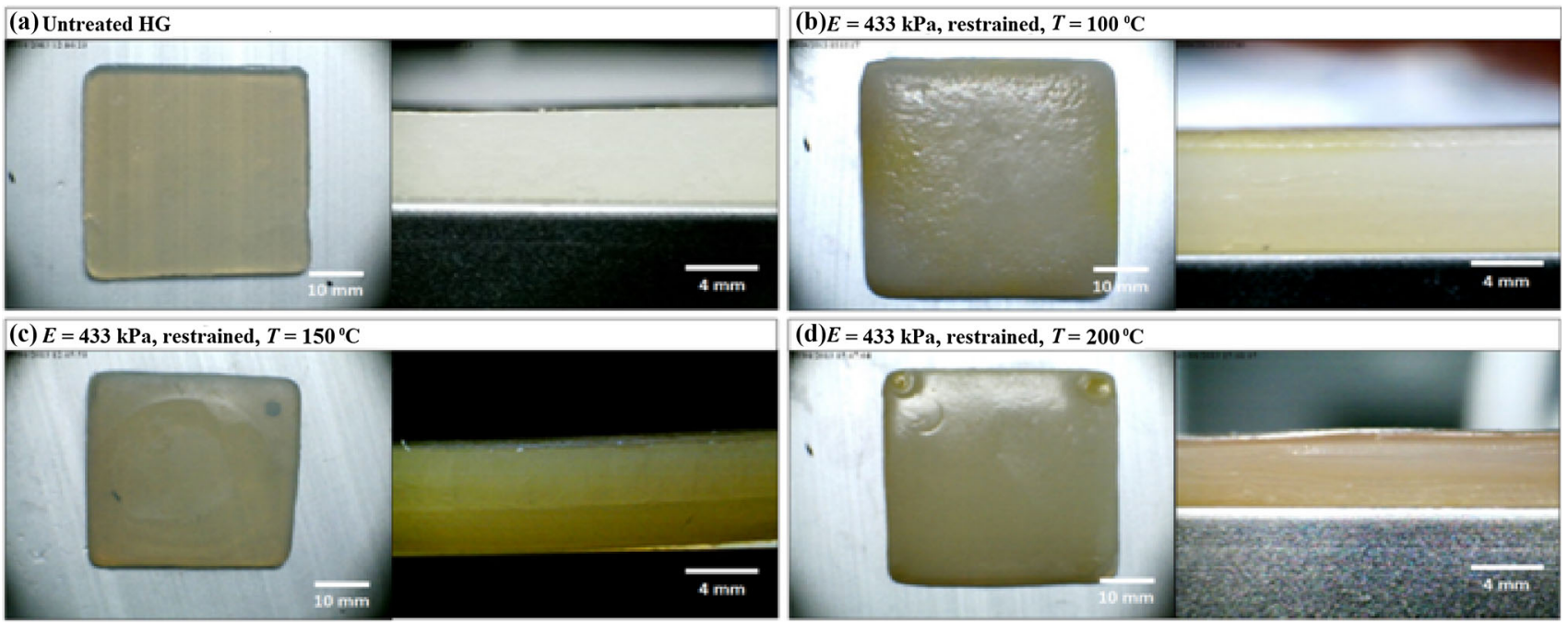

Fig. 6 Top view and profile view for $433 \mathrm{kPa}$ HGs during dehydration at 100,150 , and $200{ }^{\circ} \mathrm{C}$ in the restrained configuration
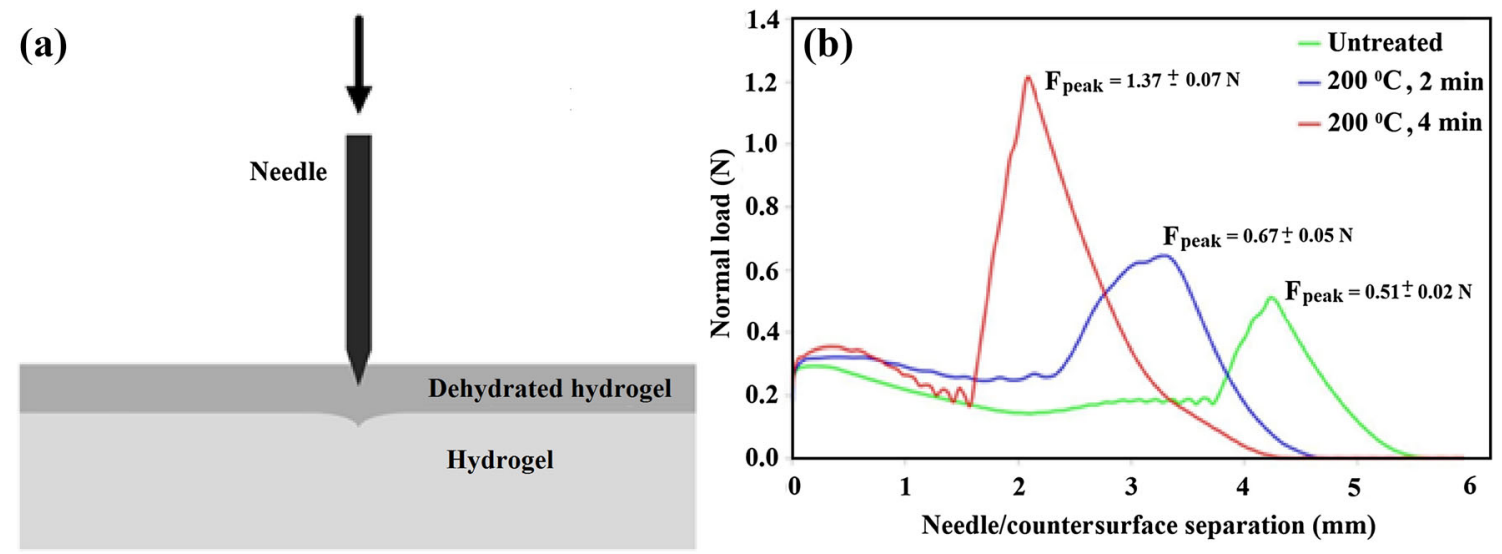

Fig. 7 a Puncture schematic, showing dehydrated hydrogel as the upper surface. b Puncture test data for 433 kPa HGs: untreated (green); dehydrated at $200{ }^{\circ} \mathrm{C}$ for $2 \mathrm{~min}$ (blue); dehydrated at $200{ }^{\circ} \mathrm{C}$ for $4 \mathrm{~min}$ (red)

Table 1 Friction coefficient of cauterized alginate against glass and poly(propylene)

\begin{tabular}{lll}
\hline Hydrogel substrate & $\begin{array}{l}\text { Friction coefficient vs glass } \\
\mu_{\text {glass }}(-)\end{array}$ & $\begin{array}{l}\text { Friction coefficient vs poly(propylene) } \\
\mu_{\mathrm{PP}}(-)\end{array}$ \\
\hline Untreated & $0.31 \pm 0.01$ & $0.12 \pm 0.01$ \\
Dehydrated, $200{ }^{\circ} \mathrm{C}, 4 \mathrm{~min}$ & $0.63 \pm 0.02$ & $0.28 \pm 0.01$ \\
\hline
\end{tabular}

150 , and $200{ }^{\circ} \mathrm{C}$ were specified; changes in sample thickness due to evaporative losses were not incorporated.

Figure 8 shows the effect of incorporating the restraining disc on the temperature of the upper surface of the $433 \mathrm{kPa}$ HG. The presence of the restraining disc decreases the rate of temperature increase within the HG. The disc also increases in temperature, and is typically $15-20{ }^{\circ} \mathrm{C}$ lower than the HG. In the restrained condition, energy from the hot plate accumulates in the aluminium disc and the HG. In the unrestrained condition, energy is lost more easily, because the HG is a good thermal conductor. This disattenuates the energy loss at the upper surface, by preventing heat transfer from the $\mathrm{HG}$ to the ambient atmosphere. The disc also means that the $\mathrm{HG}$ is heated from above and below when restrained.

Considering the $E=189 \mathrm{kPa}$ HGs in Fig. 3, at $T=100{ }^{\circ} \mathrm{C}$ the restrained $\mathrm{HG}$ loses less mass than the unrestrained HG. This is because the temperature of the restrained HG increases more slowly than the unrestrained HG. The HG temperature does not reach $100{ }^{\circ} \mathrm{C}$, the boiling point of water, for either the restrained or unrestrained condition. At $T=150$ and $200{ }^{\circ} \mathrm{C}$, the restrained HGs exhibit greater mass loss than the unrestrained HGs; why might this be? Here, the HG temperature rises to an 
Table 2 Parameters used for heat transfer simulations

\begin{tabular}{llll}
\hline Material & $\begin{array}{l}\text { Density } \\
\rho\left(\mathrm{kg} \mathrm{m}^{-3}\right)\end{array}$ & $\begin{array}{l}\text { Heat capacity } \\
C_{\mathrm{p}}\left(\mathrm{kJ} \mathrm{kg}^{-1} \mathrm{~K}^{-1}\right)\end{array}$ & $\begin{array}{l}\text { Thermal conductivity } \\
k\left(\mathrm{~W} \mathrm{~m}^{-1} \mathrm{~K}^{-1}\right)\end{array}$ \\
\hline Air & 1.204 & 1.012 & 0.025 \\
Aluminium hot plate & $\mathrm{a}$ & 0.921 & 205 \\
Hydrogel & 2700 & 4.184 & 0.591 \\
Steel disc & 1070 & 0.502 & 50 \\
\hline
\end{tabular}

${ }^{\mathrm{a} C}$ Constant temperature
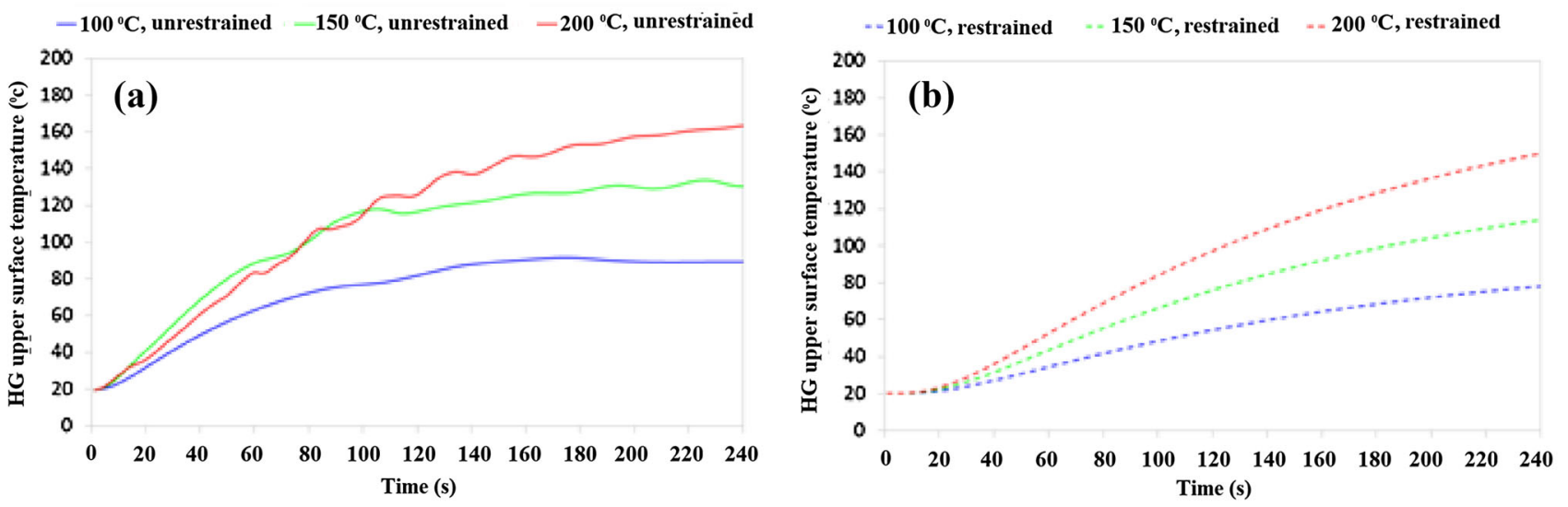

Fig. 8 Temperature of the HG sample upper surface when heated from below using a hot plate, $\mathbf{a}$ unrestrained, and $\mathbf{b}$ restrained

excess of $100{ }^{\circ} \mathrm{C}$ for both the restrained and unrestrained conditions. It is suggested that energy retained within the restrained $\mathrm{HG}$ /aluminium disc increases the rate of water evaporation, which otherwise would have caused an increase in temperature. In comparison, this energy is conducted through the unrestrained HG and is lost at the HG/air interface. The difference in behaviour occurs when the hot plate temperature is increased above the boiling point of water.

\section{Conclusions}

We report the effect of local exposure to high temperatures on the surface properties of alginate hydrogels. Rapid dehydration of the surface using temperatures in the range $100-200{ }^{\circ} \mathrm{C}$ leads to the creation of a mechanically strengthened hydrogel surface layer, exhibiting improved puncture resistance and increased coefficient of friction compared to the unheated surface. Direct contact with a surface at $200{ }^{\circ} \mathrm{C}$ for 4 min produced the most mechanically robust layer. Mechanical constraint of the hydrogel sample was important during processing, preventing curvature of the sample during cauterization, particularly at the edges.

Further investigations will study a greater variety of HG compositions, as well as explore in more detail the importance of dehydration temperature, duration, the thermal conductivity of the $\mathrm{HG}$, and the nature of the restraint material. A modified apparatus for dehydration within a humidified atmosphere, for reducing evaporative loss, is currently being designed. The possible benefit of performing the heating whilst the HG is immersed in an aqueous solution, perhaps a physiologically relevant buffer, is also under consideration. Finally, an improved understanding of the material structure remaining following the dehydration process would be useful.

Acknowledgements This work was supported by the European Union under the FP7 programme (NANOBIOTOUCH Project: FP7NMP-228844). The Zwick/Roell Z030 mechanical tester and Longshore Systems Engineering tribometer used in this research were obtained through Birmingham Science City: Innovative Uses for Advanced Materials in the Modern World (West Midlands Centre for Advanced Materials Project 2), with support from Advantage West Midlands (AWM) and partly funded by the European Regional Development Fund (ERDF). The authors thank the assistance of Elaine Mitchell throughout the course of this research.

\section{Compliance with ethical standards}

Conflict of interest All authors declare that they have no conflict of interest.

Ethical approval This article does not contain any studies with human participants or animals performed by any of the authors. 
Open Access This article is distributed under the terms of the Creative Commons Attribution 4.0 International License (http://crea tivecommons.org/licenses/by/4.0/), which permits unrestricted use, distribution, and reproduction in any medium, provided you give appropriate credit to the original author(s) and the source, provide a link to the Creative Commons license, and indicate if changes were made.

\section{References}

Adams MJ, Briscoe BJ, Johnson SA (2007) Friction and lubrication of human skin. Tribol Lett 26:239-253. doi:10.1007/s11249-0079206-0

Adams MJ, Johnson SA, Lefevre P, Levesque V, Hayard V (2013) Finger pad friction and its role in grip and touch. J R Soc Interface 10:1-19

Alsberg E, Anderson KW, Albeiruti A, Franceschi RT, Mooney DJ (2001) Cell-interactive alginate hydrogels for bone tissue engineering. J Dental Res 80:2025-2029

Augst AD, Kong JK, Mooney DJ (2006) Alginate hydrogels as biomaterials. Macromol Biosci 6:623-633

Bakakrishnan B, Mohanty M, Umashankar PR, Jayakrishnan A (2005) Evaluation of an in situ forming hydrogel wound dressing based on oxidized alginate and gelatin. Biomaterials 26:6335-6342

Bannasch H, Fohn M, Unterberg T, Bach AD, Weyand B (2003) Skin tissue engineering. Clin Plast Surg 30:573-579

Bello YM, Falabella AF, Eaglstein WH (2001) Tissue engineered skin. Am J Clin Dermatol 2:305-313

Boucard N, Viton C, Agay D, Mari E, Roger T (2007) The use of physical hydrogels of chitosan for skin regeneration following third-degree burns. Biomaterials 28:3478-3488

Chan LW, Jin Y, Heng PWS (2002a) Cross-linking mechanisms of calcium and zinc in production of alginate microspheres. Int $\mathrm{J}$ Pharm 242:255-258

Chan LW, Lee H, Heng PWS (2002b) Production of alginate microspheres by internal gelation using an emulsification method. Int J Pharm 242:259-262

Choi YS, Hong SR, Lee YM, Song KW, Moon YP (1999) Study on gelatin-containing artificial skin: I. Preparation and characteristics of novel gelatin-alginate sponge. Biomaterials 20:409-417

Currie LJ, Sharpe JR, Martin R (2001) The use of fibrin glue in skin grafts and tissue-engineered skin replacements: a review. Plast Reconstr Surg 108:1713-1726

Dormer NH, Berkland CJ, Detamore MS (2010) Emerging techniques in stratified designs and continues gradients for tissue engineering of interfaces. Ann Biomed Eng 38:2121-2141

Fuchs E, Horsley V (2008) More than one way to skin. Genes Develop 22:976-985

Grossin L, Cortial D, Saulnier B, Felix O, Chassepot A, Decher G (2009) Step-by-step built-up of biologically active cell-containing stratified films aimed at tissue engineering. Adv Mater 21:650-655

Horch RE, Kopp J, Kneser U, Beier J, Bach AD (2005) Tissue engineering of cultured skin substrates. J Cell Mol Med 9:592-608

Hunt NC, Shelton RM, Grover LM (2009) An alginate hydrogels matrix for the localized delivery of a fibroblast/keratinocyte coculture. Biotechnol J 4:730-737
Hunt NC, Smith AM, Gbureck U, Shelton RM, Grover LM (2010) Encapsulation of fibroblasts causes accelerated alginate hydrogel degradation. Acta Biomater 6:3649-3656

Johnson SA, Gorman DM, Adams MJ, Briscoe BJ (1993) The friction and lubrication of human stratum corneum. Thin Films Tribol 25:663-672

Kaklamani G, Cheneler D, Grover LM, Adams MJ, Bowen J (2014) Mechanical properties of alginate hydrogels using external gelation. J Mech Behav Biomed Mater 36:135-142

Kim GH, Ahn S, Kim YY, Cho Y, Chun W (2011) Coaxial structured collagen-alginate scaffolds: fabrication, physical properties, and biomedical application for skin tissue regeneration. J Mater Chem 21:6165-6172

Lechler T, Fuchs E (2005) Asymmetric cell divisions promote stratification and differentiation of mammalian skin. Nature 437:275-280

Lee W, Debasitis JC, Lee VK, Lee JH, Fischer K (2009) Multilayered culture of human skin fibroblasts and keratinocytes through three-dimensional freeform fabrication. Biomaterials 30:1587-1595

MacNeil S (2007) Progress and opportunities for tissue-engineered skin. Nature 445:874-880

Mao J, Zhao L, Yao K, Shang Q, Yang G, Cao Y (2003) Study of novel chitosan-gelatin artificial skin in vitro. J Biomed Mater Res A 64:301-308

Morch YA, Donati I, Strand BL, Skjåk-Bræk G (2006) Effect of $\mathrm{Ca}^{2+}, \mathrm{Ba}^{2+}$, and $\mathrm{Sr}^{2+}$ on alginate microbeads. Biomacromol 7:1471-1480

Powell HM, Boyce ST (2009) Engineered human skin fabricated using electrospun collagen-PCL blends: morphogenesis and mechanical properties. Tissue Eng A 15:2177-2187

Priya SG, Jungvid H, Kumar A (2008) Skin tissue engineering for tissue repair and regeneration. Tissue Eng B 14:105-118

Shevchenko RV, James LS, James SE (2010) A review of tissueengineered skin bioconstructs available for skin reconstruction. J R Soc Interface 7:229-258

Stevens MM, Qanadilo HF, Langer R, Shastri VP (2004) A rapidcuring alginate gel system: utility in periosteum-derived cartilage tissue engineering. Biomaterials 25:887-894

Topuz F, Henke A, Richtering W, Groll J (2012) Magnesium ions and alginate do form hydrogels: a rheological study. Soft Matter 8:4877-4881

VanGerwen DJ, Dankelman J, van den Dobbelstein JJ (2012) Needletissue interaction forces-a survey of experimental data. Med Eng Phys 34:665-680

Xie C (2012) Interactive heat transfer simulations for everyone. Phys Teach 50:237-240

Yang EK, Seo YK, Youn HH, Lee DH, Park SN, Park JK (2000) Tissue engineered artificial skin composed of dermis and epidermis. Artif Organs 24:7-17

\section{Publisher's Note}

Springer Nature remains neutral with regard to jurisdictional claims in published maps and institutional affiliations. 